\title{
Pancreatic-specific autoantibodies to glycoprotein 2 mirror disease location and behaviour in younger patients with Crohn's disease
}

Dimitrios P Bogdanos ${ }^{1 \dagger}$, Dirk Roggenbuck ${ }^{2 \dagger}$, Dirk Reinhold ${ }^{3}$, Thomas Wex ${ }^{4}$, Polychronis Pavlidis ${ }^{1}$, Ulrike von Arnim ${ }^{4}$, Peter Malfertheiner ${ }^{4}$, Alastair Forbes ${ }^{5}$, Karsten Conrad ${ }^{6}$ and Martin W Laass ${ }^{7^{*}}$

\begin{abstract}
Background: Glycoprotein 2 (GP2) was discovered as the major autoantigen of Crohn's disease (CD)-specific pancreatic autoantibodies (PAB). We investigated anti-GP2 IgA and IgG antibodies as novel serological parameters in $C D$ and assessed their association with distinct disease phenotypes.

Methods: Anti-GP2 and anti-Saccharomyces cerevisiae (ASCA) IgA and IgG were detected by ELISA employing recombinant human GP2 and phosphopeptidomannan, respectively and PAB by indirect immunofluorescence (IIF) in 271 sera, 169 with CD and 102 with ulcerative colitis (UC). As healthy controls 160 adult blood donors and 65 children were included.

Results: Anti-GP2 IgG and/or IgA were more prevalent in CD (51/169, 30.2\%) than in UC (9/102, 8.9\%) patients and in controls $(9 / 225,4 \%)(p<0.001$ respectively). ASCA IgG and/or IgA were present in 60/169 (35.5\%) in CD and in 7/ $102(6.9 \%)$ in UC patients $(p<0.001)$. CD patients with ileocolonic location (L3) showed a significantly higher prevalence of anti-GP2 and ASCA IgA and/or IgG (40/113 and 48/113, respectively; $p<0.05$ for both comparisons), whereas CD patients with colonic location (L2) revealed a significantly diminished prevalence for these autoantibody specificities (2/32 and 5/32, respectively, $\mathrm{p}<0.05$ for both). Anti-GP2 IgG were significantly more prevalent in CD patients with stricturing behaviour (B2) and perianal disease $(7 / 11, p<0.02)$ and less prevalent in those with penetrating behaviour (B3) and perianal disease (4/31, $\mathrm{p}<0.05)$. The occurrence of anti-GP2 IgA and/or IgG was significantly more prevalent in CD patients with age at diagnosis of $\leq 16$ years $(16 / 31, p<0.009)$. Prevalence of one or more anti-GP2 or ASCA IgA and/or IgG was significantly higher in L3, B2, and A1 and lower in L2 (68/113, 27/41, 23/31, 6/32; $\mathrm{p}<0.04$, respectively).
\end{abstract}

Conclusions: Anti-GP2 lgG and IgA, constituting novel CD specific autoantibodies, appear to be associated with distinct disease phenotypes identifying patients at a younger age, with ileocolonic location, and stricturing behaviour with perianal disease.

Keywords: Autoantibody, Autoantigen, Autoimmunity, Crohn's disease, Gastroenterology, Glycoprotein 2, Inflammatory bowel disease

\footnotetext{
*Correspondence: martin.laass@uniklinikum-dresden.de

${ }^{\dagger}$ Equal contributors

${ }^{7}$ Children's Hospital, Technical University Dresden, 01307 Dresden,

Fetscherstraße 74, Germany

Full list of author information is available at the end of the article
}

\section{Ciomed Central}

(c) 2012 Bogdanos et al.; licensee BioMed Central Ltd. This is an Open Access article distributed under the terms of the Creative Commons Attribution License (http://creativecommons.org/licenses/by/2.0), which permits unrestricted use, distribution, and reproduction in any medium, provided the original work is properly cited. 


\section{Background}

The most prevalent clinical entities of inflammatory bowel disease (IBD), Crohn's disease (CD) and ulcerative colitis (UC), affect as many as one in 250 individuals among Caucasians, and demonstrate an increase in other ethnic populations [1-4]. Although the pathophysiology of IBD is poorly understood, there is scientific evidence demonstrating that a damaged mucosal barrier is leading to mucosal inflammation triggered by intestinal bacteria in genetically predisposed individuals $[3,5]$. The intestinal inflammation in $\mathrm{CD}$ patients affects all layers of the bowel wall and adventitia and in contrast to UC is not confined to rectum and colon, but can be found throughout the alimentary tract [1].

Immune responses to disease-specific autoantigens also appear to be a prominent feature of $\mathrm{CD}$, and are possibly involved in the pathogenesis of IBD [3]. Glycoprotein 2 (GP2) has recently been identified as the major autoantigenic target of CD-specific pancreatic autoantibodies (PAB) [6-8]. GP2 is mainly expressed as glycosyl phosphoinositol (GPI) membrane-anchored protein in the pancreas and released together with zymogens into the duodenum upon hormonal or neuronal stimulation $[9,10]$. Interestingly, GP2 has also been demonstrated to be a membrane-anchored receptor of microfold cells ( $M$ cells) in human intestinal Peyer's patches (PP) and to be over-expressed at the site of $\mathrm{CD}$ inflammation in contrast to UC [6,11]. GP2 is involved in transcytosis of bacterial antigens, the presentation of whom by dendritic cells give rise to an antigen-specific immune response [11]. GP2 interacts with epithelial and activated T cells, binds to scavenger receptor on endothelial cells, and modulates innate and adaptive immune responses supporting a potential pathophysiological role [2,12].

Patients with IBD demonstrate disease-specific antibodies that may aid in the differential diagnosis of IBD, especially in the case of unclassified IBD [13,14]. Antibodies to bacterial peptides and glycans have been considered diagnostic markers of IBD but their prognostic significance is a matter of debate [15-17]. While the diagnostic significance of anti-GP2 antibodies in IBD has been studied in some detail, the clinical significance of these autoantibodies is unclear [2,18-21]. Thus, it is currently unknown whether humoral autoreactivity to GP2 or PAB respectively may assist in the prediction or stratification of disease activity or whether these autoantibodies are associated with specific clinical features [2,19,21-23].

The aim of the present study was to investigate the association of anti-GP2 antibodies with disease characteristics in $\mathrm{CD}$ in comparison with anti-Saccharomyces cerevisiae antibodies (ASCA), an established serological marker of $\mathrm{CD}$. Here, we provide evidence for the first time that humoral autoreactivity to GP2 in CD appears to be associated with distinct clinical phenotypes.

\section{Methods}

\section{Patient population}

Serum samples from 169 patients with CD (median of age: 36 years) and 102 patients with UC were collected at the Children's hospital of the Technical University Dresden, at the Department of Gastroenterology, Hepatology, and Infectious Diseases of the Otto-von-Guericke University Magdeburg, and at the Department of Gastroenterology and Clinical Nutrition, University College Hospital, London. All samples were taken at the time of consent and enrolment. Demographic and clinical characteristics of patients with $\mathrm{CD}$ are shown in Table 1. In total, 225 controls (median of age: 35 years, min 9 months, max 85 years) were recruited: 165 healthy adult blood donors and 65 children, who were admitted for eye surgery correcting their strabismus but were otherwise healthy. As control group for the comparison with patients with onset of disease below 17 years, the 65 children of the control group (median of age: 6 years, min 9 months, max 16 years) were selected.

Patients with CD were assigned a behavioural phenotype according to the Montreal classification [24]. Patients with unclassified IBD were excluded from the study. Correctness of diagnosis had been confirmed for all patients by 3 investigators (UA, AF, and MWL). Median age of patients with UC was 47 years (minimum 17, maximum 92) and 57 from 102 patients were female

\section{Table 1 Demographic and clinical characteristics of patients with Crohn's disease}

\begin{tabular}{ll}
\hline Female, $\mathrm{n}(\%)$ & $\mathrm{CD}(\mathbf{n}=\mathbf{1 6 9})$ \\
Median age at study (max,min) & $102(60.3)$ \\
Age at diagnosis (years) & $36(8,87)$ \\
below 17 years (A1), n (\%) & $31(18.3)$ \\
between 17 and 40 years (A2), n (\%) & $19(11.2)$ \\
above 40 years (A3), n (\%) & $119(70.4)$ \\
Location & \\
ileal (L1), n (\%) & $24(14.2)$ \\
colonic (L2), n (\%) & $32(18.9)$ \\
ileocolonic (L3), n (\%) & $113(66.9)$ \\
upper disease, modifier (L4), n (\%) & $12(7.1)$ \\
Behavior & \\
non-stricturing, non-penetrating (B1), n (\%) & $86(50.9)$ \\
stricturing (B2), n (\%) & $41(24.3)$ \\
penetrating (B3), n (\%) & $42(24.8)$ \\
perianal disease modifier (p), n (\%) & $62(36.7)$ \\
non-stricturing, non-penetrating (B1p), n (\%) & $20(11.8)$ \\
stricturing (B2p), n (\%) & $11(6.5)$ \\
penetrating (B3p), n (\%) & $31(18.3)$ \\
\hline
\end{tabular}


(55.9\%). The diagnoses of CD and UC were based upon standard clinical, radiological, endoscopical and histological criteria [25,26].

The study was approved by the local ethics committees and conducted in accordance with the Helsinki declaration. Written informed consent was obtained from each individual. Aliquots of serum samples have been stored at $-80{ }^{\circ} \mathrm{C}$ until use.

\section{Detection of antibodies to GP2 by ELISA}

Anti-GP2 (IgA and IgG) autoantibodies were detected in sera of patients employing an ELISA from Generic Assays (Dahlewitz/Berlin, Germany), in accordance with the manufacturer's instructions. This ELISA is based on recombinant human GP2 expressed in Spodoptera frugiperda 9 cells as solid-phase antigen [18]. For expression of GP2 by the baculovirus system, the plasmid pcDNA3.1+GP2-trunc-Thrombin-His is used which codes the amino acid sequence of GP2 isoform BAA88166 (pancreatic zymogen granule membrane associated protein GP2 alpha form) corresponding to the official isoform 2 (NP_001493) without 8 amino acids at the N-terminal end [27].

The anti-GP2 IgG ELISA displayed an intra-assay variability of $5.7 \%$ and an inter-assay variability of $5.0 \%$ for sera with elevated concentrations of $24.3 \mathrm{U} / \mathrm{ml}$ and $26.9 \mathrm{U} / \mathrm{ml}$, respectively. The anti-GP2 IgA ELISA revealed an intra-assay variability of $5.9 \%$ and an interassay variability of $5.0 \%$ for sera with an elevated concentration of $17.8 \mathrm{U} / \mathrm{ml}$ and $18.5 \mathrm{U} / \mathrm{ml}$, respectively. The functional assay sensitivities for anti-GP2 IgG and IgA determined as described elsewhere were assessed at $2.4 \mathrm{U} / \mathrm{ml}$ and $1.8 \mathrm{U} / \mathrm{ml}$, respectively [28].

\section{Detection of antibodies to Saccharomyces cerevisiae by ELISA}

In view of published studies reporting the frequent cooccurrence of CD-specific autoantibodies like $\mathrm{PAB}$ or in particular anti-GP2 and ASCA, and in order to compare anti-GP2 with ASCA, serum samples from patients were also tested for this anti-microbial reactivity. ASCA were determined as described previously, employing commercially available ELISA (ASCA IgA, ASCA IgG, GA Generic Assays $\mathrm{GmbH}$, Dahlewitz, Germany) according to the recommendations of the manufacturer as reported elsewhere [13].

The intra-assay coefficient of variation was $2.0 \%$ for a sample containing $76 \mathrm{U} / \mathrm{ml}$ and $2.8 \%$ for a sample containing $78 \mathrm{U} / \mathrm{ml}$ of ASCA IgA and ASCA IgG, respectively. The inter-assay coefficient of variation was $5.9 \%$ for a sample containing $72 \mathrm{U} / \mathrm{ml}$ and $1.8 \%$ for a sample containing $81 \mathrm{U} / \mathrm{ml}$ of ASCA IgA and ASCA IgG, respectively.

\section{Assessment of pancreatic antibodies (PAB)}

Antibodies to exocrine pancreas were detected by running patient samples on commercially available pancreas tissue sections according to the recommendations of the manufacturer (GA Generic Assays GmbH, Dahlewitz, Germany). Briefly, tissue sections were incubated in a moist chamber at RT for 30 minutes with $50 \mu \mathrm{l}$ of serially diluted serum, starting at a dilution of 1 in 20 as reported elsewhere [18].

Samples were subsequently washed, embedded, and analysed with the automated interpretation system AKLIDES 40 (Medipan, Dahlewitz/Berlin, Germany) as described for other IIF tests [29]. Samples with a titre of 1:20 were considered borderline and samples with a titre of 1:40 or higher were scored positive.

\section{Statistical analysis}

A Kolmogorov-Smirnov test was used to analyse the data for normality. Differences between groups were tested by Kruskal-Wallis and Fisher's exact test with two-tailed probability. Spearman's rank correlation test was applied for within group comparison. P values $<0.05$ were considered significant. Assay performance including sensitivity, specificity, positive and negative likelihood ratio and receiver-operating characteristics (ROC) curve analysis were determined using Medcalc statistical software (Medcalc, Mariakerke, Belgium). The measured values were expressed as medians with 95\% confidential intervals (CI).

\section{Results}

\section{Patient cohorts}

To investigate humoral autoreactivity to GP2 in IBD, 271 patients with IBD (169 CD patients, 102 UC patients) and 225 controls were included into this multicentre study with one British and two German gastroenterology departments. Patient characteristics are depicted in Table 1.

\section{Comparison of antibodies to GP2 with PAB in IBD patients and controls}

Recombinant human GP2 immobilised on microtiter plates was employed to detect anti-GP2 IgG and IgA antibodies in sera of 169 patients with CD, 102 patients with UC and 225 controls (Table 2).

There was a significantly higher prevalence of antiGP2 IgA (22/169, 13\%), IgG (48/169, 28.4\%) and IgA and/or IgG $(51 / 169,30.2 \%)$ in CD patients compared to UC patients $(2 / 102,2.0 \%$; 8/102, $7.8 \%$; $9 / 102,8.8 \%$, respectively) and in controls (3/225, 1.3\%; 6/225, 2.7\%; 9 / $225,4 \%$; respectively) in accordance to the KruskalWallis test ( $\mathrm{p}=0.001$, respectively).

Prevalence rates for anti-GP2 IgA [7/66 (10.6\%) vs 15/ $103(14.6 \%)]$ and IgG [16/66 (24.2\%) vs 32/103 (31.1\%)] as well ASCA IgA [16/66 (24.2\%) vs 23/103 (22.3\%)] and 
Table 2 Antibody distribution in 169 patients with Crohn's disease (CD), 102 patients with ulcerative colitis (UC), and 225 controls

\begin{tabular}{|c|c|c|c|c|}
\hline & \multicolumn{2}{|l|}{ CD } & \multirow{2}{*}{$\frac{U C}{(n=102)}$} & \multirow{2}{*}{$\begin{array}{l}\text { controls } \\
(n=225)\end{array}$} \\
\hline & All CD patients $(n=169)$ & ASCA negative CD patients $(n=109)$ & & \\
\hline Anti-GP2 IgA, (\%) & $22(13.0)$ & $9(8.2)$ & $2(2.0)$ & $3(1.3)$ \\
\hline Anti-GP2 lgG, (\%) & $48(28.4)$ & $25(22.9)$ & $8(7.8)$ & $6(2.7)$ \\
\hline Anti-GP2 IgA and/or lgG, (\%) & $51(30.2)$ & $26(23.9)$ & $9(8.8)$ & $9(4.0)$ \\
\hline$P A B>=1 / 20,(\%)$ & $74(43.8)$ & $45(41.3)$ & $24(23.5)$ & nd \\
\hline $\mathrm{PAB}>=1 / 40,(\%)$ & $65(38.5)$ & $38(34.9)$ & $21(20.6)$ & nd \\
\hline ASCA IgA, (\%) & $39(23.1)$ & - & $3(2.9)$ & $2(0.9)$ \\
\hline ASCA IgG, (\%) & $48(28.4)$ & - & $5(4.9)$ & $7(3.1)$ \\
\hline ASCA IgA and/or lgG, (\%) & $60(35.5)$ & - & $7(6.9)$ & $8(3.5)$ \\
\hline ASCA and/or anti-GP2, (\%) & $86(50.9)$ & - & $15(14.7)$ & $16(7.1)$ \\
\hline \multicolumn{5}{|l|}{$\begin{array}{l}\text { Number of positive antibodies } \\
\text { detected by ELISA }\end{array}$} \\
\hline 0 & $83(49.1)$ & $83(76.1)$ & $87(85.3)$ & $208(92.4)$ \\
\hline 1 & $40(23.7)$ & $18(16.5)$ & $12(11.8)$ & $13(5.8)$ \\
\hline 2 & 28 (16.6) & $8(7.3)$ & $3(2.9)$ & $4(1.8)$ \\
\hline 3 & $11(6.5)$ & - & $0(0.0)$ & $0(0.0)$ \\
\hline 4 & $7(4.1)$ & - & $0(0.0)$ & $0(0.0)$ \\
\hline
\end{tabular}

$\mathrm{ASCA}$, antibody to mannan of Saccharomyces cerevisiae; $\mathrm{Cl}$, confidence interval; GP2, zymogen granule membrane glycoprotein 2; nd, not done; $\mathrm{PAB}$, pancreatic autoantibody.

IgG [17/66 (25.8\%) vs 31/103 (30.1\%)] were not significantly different comparing German and English patients with $\mathrm{CD}$, respectively. Pancreatic autoantibodies detected by IIF also demonstrated a higher prevalence in CD compared to UC patients [65/169 (38.5\%) vs 21/102 (20.6\%); $\mathrm{p}<0.003$ ] and were significantly correlated with anti-GP2 IgG (Spearman's coefficients of rank correlation [rho] = 0.466, 95\% interval of confidence [CI]: 0.367-0.554, $\mathrm{p}<0.001)$. However, in UC patients the prevalence of PAB at titres $\geq 1: 40$ was significantly higher $(21 / 102,20.6 \%)$ compared to anti-GP2 IgG (8/102, 7.8\%) and even with anti-GP2 IgG and/or IgA $(9 / 102,8.8 \%)(\mathrm{p}<0.02$ and $\mathrm{p}<0.03$, respectively). In CD patients the difference in the occurrence of $\mathrm{PAB} \geq 1: 40(65 / 169,38.5 \%)$ and anti-GP2 (IgG: 48/169, 24.8\% IgG and/or IgA: 51/169, 30.2\%) did not reach significance $(p=0.064$ and $p=0.108$, respectively). There is good accordance between anti-GP2 and anti-PAB positivity. From $51 \mathrm{CD}$ patients with anti-GP2 IgA and/or IgG positivity 45 (88\%) showed also PAB positivity. Conversely, from 65 patients with $\mathrm{PAB}$ positivity 20 were negative for both anti-GP2 IgA and IgG respectively.

\section{Comparison of antibodies to GP2 with ASCA in IBD patients}

To compare anti-GP2 reactivity with an established antibody marker in IBD patients, ASCA IgA and IgG were determined in both patient cohorts. Like anti-GP2 antibodies, ASCA IgA (39/169, 23.1\%), IgG (48/169, 28.4\%), and IgA and/or IgG $(60 / 169,35.5 \%)$ demonstrated a significantly higher prevalence in $\mathrm{CD}$ than in UC patients [3/102 (2.9\%), 5/102 (4.9\%), 7/102 (6.9\%), respectively; $\mathrm{p}<0.001$, for all comparisons] and in controls (Table 2). Receiver operating characteristics curve analysis revealed similar AUC values for the detection of ASCA and antiGP2 isotypes (Figure 1). Only the comparison of anti-GP2 IgA and ASCA IgG showed significantly different areas under the curve (AUC) values (difference between areas: 0.0886, 95\% CI: 0.0105-0.167; p < 0.03).

IgA and IgG reactivity to GP2 and Saccharomyces cerevisiae were significantly correlated (rho $=0.422,95 \% \mathrm{CI}$ : $0.340-0.533$; rho $=0.335,95 \%$ CI: 0.225 to $0.436, p<0.001$, respectively). However, 26 (23.9\%) of ASCA negative patients demonstrated either IgA or IgG reactivity to GP2 (Table 2).

\section{Assay performance characteristics for anti-GP2, ASCA, and PAB}

Assay performance characteristics for the detection of anti-GP2 IgA and IgG were compared to corresponding ASCA and PAB values and the results are summarized in Table 3. Regarding the serological discrimination of CD and UC, ASCA and anti-GP2 antibodies alone have medium positive likelihood ratios (LR) indicating the ratio between the probability of a positive test result given the presence of the disease $(+\mathrm{LR})$ and the probability of a positive test result given the absence of the disease (-LR). Interestingly, $\mathrm{PAB}$ demonstrated an even lower +LR despite the higher prevalence in $\mathrm{CD}$ patients. 


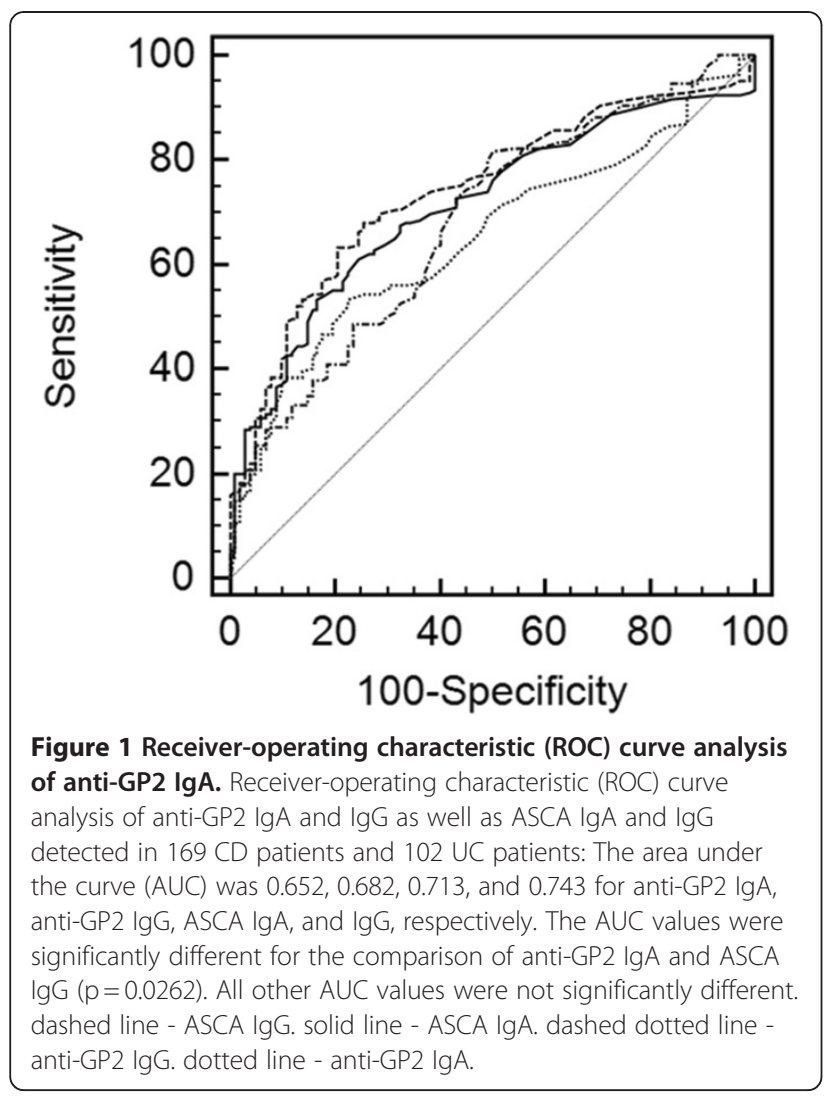

The combination of ASCA and anti-GP2 antibody assessment improves the +LR values regarding the serological differentiation of $\mathrm{CD}$ and $\mathrm{UC}$. The detection of at least 2 ELISA-antibodies thereof reveals a $+\mathrm{LR}$ for $\mathrm{CD}$ of 9.2. Only $3 / 102(2.9 \%)$ patients suffering from UC displayed antibody reactivities scoring positive in two of the four ELISAs. The determination of 3 or more antibodies seen in 18/169 CD patients is highly specific for CD (100\%) resulting in an infinite $+\mathrm{LR}$.

\section{Association of anti-GP2 and ASCA with location of disease} Employing the Montreal classification of IBD, CD patients were stratified according to age at diagnosis, location, and behaviour of disease (Table 1). Fisher's exact test revealed a significantly higher prevalence of IgA and/or IgG reactivity to GP2 $(40 / 113,35.4 \%)$ in CD patients with ileocolonic location of disease (L3) $(11 / 56$, 19.6\%; p < 0.05) (Table 4).

In contrast, there was a significantly lower prevalence thereof in CD patients characterized by a colonic location of disease (L2) [2/32 (6.2\%) vs 49/137 (35.8\%); $\mathrm{p}<0.001]$. A similar pattern was seen for ASCA IgA and/or IgG [L3: 48/113 (42.5\%) vs 12/56 (21.4\%); L2: 5/ 32 (15.6\%) vs 55/137 (40.1\%); $\mathrm{p}<0.001, \mathrm{p}<0.02$; respectively). While a significantly lower prevalence in $C D$ patients with L2 was also detected for anti-GP2 IgA [0/ $32(0.0 \%)$ vs 22/132 (16.7\%)], anti-GP2 IgG [2/32 (6.2\%) vs $46 / 137$ (33.5\%)], and the simultaneous appearance of both isotypes $[2 / 32(6.2 \%)$ vs $49 / 137$ (35.8\%)], only the occurrence of anti-GP2 IgG was significantly higher in CD patients with L3 [38/113 (33.6\%) vs 10/56 (17.9\%)] (Table 4). In contrast, the increased prevalence of PAB in CD with L3 [49/113 (43.4\%) vs 16/56 (28.6\%)] did not reach significance and only the occurrence thereof in CD with L2 was significantly reduced [7/32 (21.9\%) vs 58/137 (42.3\%); $\mathrm{p}<0.05]$.

Table 3 Performance characteristics of anti-GP2 and ASCA IgA/lgG and PAB investigating 169 CD patients and 102 UC patients

\begin{tabular}{lllllllll}
\hline & sensitivity & $\mathbf{9 5 \%} \mathbf{C l}$ & specificity & $\mathbf{9 5 \%} \mathbf{C l}$ & $\mathbf{+ L R}$ & $\mathbf{9 5 \%} \mathbf{C l}$ & $\mathbf{- L R}$ & $\mathbf{9 5 \%} \mathbf{C l}$ \\
\hline anti-GP2 IgA & 13.0 & $8.3-19.0$ & 98.0 & $93.0-99.8$ & 6.6 & $1.6-27.4$ & 0.9 & $0.8-1.0$ \\
anti-GP2 IgG & 28.4 & $21.7-35.8$ & 92.2 & $85.1-96.6$ & 3.6 & $1.8-7.3$ & 0.8 & $0.7-0.9$ \\
anti-GP2 IgA or lgG & 30.2 & $23.4-37.7$ & 91.2 & $83.9-95.9$ & 3.4 & $1.8-6.6$ & 0.8 & $0.7-0.9$ \\
ASCA IgA & 23.1 & $17.0-30.2$ & 97.1 & $91.6-99.4$ & 7.8 & $2.5-24.7$ & 0.8 & $0.7-0.9$ \\
ASCA IgG & 28.4 & $21.7-35.8$ & 95.1 & $88.9-98.4$ & 5.8 & $2.4-14.1$ & 0.8 & $0.7-0.8$ \\
ASCA IgA or lgG & 35.5 & $28.3-43.2$ & 93.1 & $86.4-97.2$ & 5.2 & $2.5-10.9$ & 0.7 & $0.6-0.8$ \\
PAB $\geq 1 / 20$ & 45.4 & $37.6-53.4$ & 76.5 & $67.0-84.3$ & 1.9 & $1.3-2.8$ & 0.7 & $0.6-0.8$ \\
PAB $\geq 1 / 40$ & 38.5 & $31.1-46.2$ & 79.4 & $70.3-86.8$ & 1.9 & $1.2-2.9$ & 0.8 & $0.7-0.9$ \\
at least 1 ab* & 50.9 & $43.1-58.6$ & 85.3 & $76.9-91.5$ & 3.5 & $2.1-5.6$ & 0.6 & $0.5-0.7$ \\
at least 2 ab* & 27.2 & $20.7-34.6$ & 97.1 & $91.6-99.4$ & 9.2 & $3.0-29.0$ & 0.8 & $0.7-0.8$ \\
at least 3 ab* & 10.6 & $6.4-16.3$ & 100.0 & $96.4-100.0$ & $\infty$ & & 0.9 & $0.8-0.9$ \\
at least 4 ab* & 4.1 & $1.7-8.3$ & 100.0 & $96.4-100.0$ & $\infty$ & & $0.1-1.0$ \\
\hline
\end{tabular}

Sensitivity, specificity and likelihood ratios were calculated using a cut-off of $20 \mathrm{U} / \mathrm{ml}$ for all ELISA and a titre of $1 / 20$ and $1 / 40$ of IIF.

$\mathrm{ab}$, antibody; ASCA, antibody to mannan of Saccharomyces cerevisiae; CD, Crohn's disease; CI, confidence interval; ELISA, enzyme-linked immunosorbent assay; GP2, zymogen granule membrane glycoprotein 2; LR, likelihood ratio; PAB, pancreatic autoantibody; UC, ulcerative colitis; *anti GP2 and/ or ASCA. 
Table 4 Association of anti-GP2, ASCA, and PAB with disease characteristics in CD: $p$ values for elevated (bold) or diminished (italic) prevalence of samples with anti-GP2, ASCA, or PAB in 169 CD patients detected by ELISAs and IIF, respectively

\begin{tabular}{|c|c|c|c|c|c|c|c|c|c|c|}
\hline & \multicolumn{4}{|c|}{ anti-GP2 } & \multicolumn{4}{|c|}{ ASCA } & \multicolumn{2}{|l|}{ PAB } \\
\hline & $\lg A$ & $\lg G$ & $\lg A$ or $\lg G$ & $\lg A$ and $\lg G$ & $\lg A$ & $\lg G$ & $\lg A$ or $\lg G$ & $\lg A$ and $\lg G$ & $>=1 / 20$ & $>=1 / 40$ \\
\hline \multicolumn{11}{|l|}{ L1 } \\
\hline L2 & $<0.02$ & $<0.002$ & $<0.001$ & $<0.03$ & & & $<0.02$ & & & $<0.05$ \\
\hline L3 & & $<0.05$ & $<0.05$ & & & $<0.05$ & $<0.002$ & & & \\
\hline \multicolumn{11}{|l|}{ L4 } \\
\hline \multicolumn{11}{|l|}{ B1 } \\
\hline \multicolumn{11}{|l|}{ B2 } \\
\hline B3 & & $<0.02$ & $<0.04$ & & & & & & & \\
\hline \multicolumn{11}{|l|}{ B1p } \\
\hline B2p & & $<0.02$ & $<0.02$ & & & & & & & \\
\hline B3p & & $<0.05$ & & & & & & & & \\
\hline A1 & & $<0.004$ & $<0.009$ & $<0.001$ & & $<0.004$ & & & $<0.002$ & $<0.001$ \\
\hline \multicolumn{11}{|l|}{$A 2$} \\
\hline A3 & & & & & & & & & & $<0.02$ \\
\hline
\end{tabular}

\section{Association of anti-GP2 and ASCA with behaviour of disease}

Crohn's disease patients with penetrating disease (B3) demonstrated a significantly lower prevalence of antiGP2 IgG alone and of anti-GP2 IgA and/or IgG [6/42 (14.3\%) vs $42 / 127$ (33.1\%) and $7 / 42$ (16.7\%) vs $44 / 127$ (34.6\%); $\mathrm{p}<0.02, \mathrm{p}<0.04$, respectively] (Table 4). The diminished appearance of anti-GP2 IgA (4/42, 9.5\%) did not reach significance. Interestingly, $C D$ patients with stricturing and perianal disease (B2p) showed an elevated occurrence of anti-GP2 IgG alone and of anti-GP2 IgA and/or IgG [7/11 (63.6\%) vs 41/158 (25.9\%) and 7/ 11 (63.6\%) vs 44/158 (27.8\%); $\mathrm{p}<0.02$, respectively]. Interestingly, there was also a significant lower prevalence of anti-GP2 IgG in CD patients with penetrating and perianal disease $[4 / 31$ (12.9\%) vs 44/138 (31.9\%), $\mathrm{p}<0.05]$. In contrast, there was no significant association for ASCA and PAB with disease behaviour detectable.

Apart from a significantly higher prevalence of $C D$ specific IgG in patients with B2p $(9 / 11,81.8 \%)$ compared to $\operatorname{IgA}(2 / 11,18.2 \% ; \mathrm{p}<0.03)$, there was no further difference in the isotype prevalence regarding anti-GP2 or ASCA.

\section{Association of anti-GP2 and ASCA with age at diagnosis}

Crohn's disease patients with an age less than 17 years at diagnosis (A1) demonstrated a significantly higher prevalence of CD-specific IgG antibodies [anti-GP2 IgG 16/31 (51.6\%) vs 32/138 (23.2\%), ASCA IgG 15/31 (48.4\%) vs 33/138 (23.9\%), PAB 22/31 (71.0\%) vs 43/138 (31.2\%); $\mathrm{p}<0.004, \mathrm{p}<0.004, \mathrm{p}<0.001$, respectively]. Interestingly, the combination of IgA and/or IgG to GP2 also revealed a significantly higher prevalence in CD patients with A1 [16/31 (51.6\%) vs 35/138 (25.4\%), $\mathrm{p}<0.009$ ]. Remarkably, CD specific IgG occurred less prevalent in $\mathrm{CD}$ patients with an age at diagnosis above 40 years [anti-GP2 IgG: 2/19 (10.5\%) vs 46/150 (30.7\%); ASCA IgG: 4/19 (21.1\%) vs 44/150 (29.3\%)], however, only the less prevalent appearance of $\mathrm{PAB}$ reached significance in this patient group $[2 / 19(10.5 \%)$ vs $63 / 150$ (42.0\%); $\mathrm{p}<0.02]$. Although anti-GP2 IgA was more prevalent in CD patients with A1 than ASCA IgA [10/31 (32.3) vs $9 / 31$ (29.0\%)] and less in CD patients with A3 $(1 / 19,5.3 \%$ vs $2 / 19,10.5 \%)$, all prevalence rates were not significantly different compared with the respective patient groups regarding age at diagnosis. To exclude a possible bias regarding higher prevalence of antibody occurrence in younger individuals, we selected a group of controls with an age below 17 years. There were no significant different prevalences of CD specific antibodies compared to the 160 adult blood donors. However, the prevalence of $C D$ specific antibodies was significantly higher in the $C D$ patient group consisting of 31 individuals with A1 than in this particular control group [antiGP2 IgA: 10/31 (32.3\%) vs 1/65 (1.5\%), anti-GP2 IgG 16/ 31 (51.6\%) vs 2/65 (3.1\%), ASCA IgA: 9/31 (29.0\%) vs $1 /$ 65 (1.5\%), ASCA IgG 15/31 (48.4\%) vs $1 / 65$ (1.5\%); $\mathrm{p}<0.001$, respectively].

\section{Association of the combined analysis of anti-GP2 and ASCA with disease phenotypes}

Positivity for antibodies to GP2 or Saccharomyces cerevisiae in at least one of the four ELISAs investigated was significantly associated with ileocolonic disease location 
[68/113 (60.2\%) vs 18/56 (32.1\%); $\mathrm{p}<0.001]$, stricturing behaviour [27/41 (65.9\%) vs 59/128 (46.1\%); p < 0.04], and age at diagnosis below 17 years [23/31 (74.2\%) vs 63/138 (45.7\%), $\mathrm{p}<0.006$ ] in CD patients (Table 5). Occurrence of at least one positive antibody was significantly less prevalent in CD patients with colonic location [6/32 (18.8\%) vs 80/137 (58.4\%); p<0.001]. Remarkably, the highly specific occurrence of three or more antibodies in $\mathrm{CD}(\mathrm{n}=18)$ was significantly associated with ileocolonic disease location [16/113 (14.2\%) vs $2 / 56$ (3.6\%); $\mathrm{p}<0.04]$ and young age (A1) in CD [7/31 (22.6\%) vs $11 / 138$ (8.0\%); $\mathrm{p}<0.03]$.

\section{Discussion}

The major findings of the present study are that antiGP2 antibodies are present in approximately 30\% of patients with $\mathrm{CD}$, and appear to identify cases with an earlier onset, ileocolonic location, and stricturing behaviour with perianal disease. Our findings support the notion that anti-GP2 antibodies are diagnostically and clinically-relevant markers of $\mathrm{CD}$ and can assist physicians in the management of patients with clinical suspicion of IBD. Not only anti-GP2 antibody testing by ELISA shows a remarkable positive correlation with PAB by IIF but also appears to allow better discrimination of low titre or borderline positive $\mathrm{PAB}$ by IIF and seems therefore more specific for $\mathrm{CD}$ than $\mathrm{PAB}$ testing. This supports the notion that anti-GP2 antibody detection can be a supplementary tool for the testing of $\mathrm{CD}$ -

\begin{tabular}{|c|c|c|c|c|}
\hline & \multicolumn{4}{|c|}{ Number of antibodies detected by ASCA and anti-GP2 ELISA } \\
\hline & at least one & at least two & at least three & Four \\
\hline \multicolumn{5}{|l|}{ L1 } \\
\hline L2 & $<0.001$ & $<0.05$ & $<0.03$ & \\
\hline L3 & $<0.001$ & & $<0.04$ & \\
\hline \multicolumn{5}{|l|}{ L4 } \\
\hline \multicolumn{5}{|l|}{ B1 } \\
\hline B2 & $<0.04$ & & & \\
\hline \multicolumn{5}{|l|}{ B3 } \\
\hline \multicolumn{5}{|c|}{ B1p } \\
\hline \multicolumn{5}{|c|}{ B2p } \\
\hline \multicolumn{5}{|c|}{ B3p } \\
\hline A1 & $<0.006$ & $<0.007$ & $<0.03$ & $<0.003$ \\
\hline \multicolumn{5}{|c|}{ A2 } \\
\hline A3 & & & & \\
\hline
\end{tabular}

specific pancreatic antibodies complementing or even replacing the laborious IIF technique [2].

Cohorts from clinical centres recruiting patients participating in the present study reported a $\sim 30 \%$ anti-GP2 seropositivity in patients with CD [18-20]. However, accurate estimation of the overall prevalence of anti-GP2 antibodies in patients with IBD could not be carried out up so far, as testing of serum samples was performed in different laboratories and at various time points [18-20]. The systematic approach used in the present study, employing simultaneous testing of all coded samples in one laboratory and by the same immunodiagnostician (DRo), allowed for continuity of testing, thus permitting safer conclusions regarding the exact frequency of antiGP2 antibodies in IBD. The approximately 30\% antiGP2 seropositivity rate may indeed be an underestimation of the real prevalence in newly diagnosed cases with $\mathrm{CD}$, if antibodies are diminished over the course of the disease as an effect of the administration of biological agents and immunosuppressive treatment for CD $[2,18,19]$. In fact, sharp decline of IgG anti-GP2 antibodies has been described in CD during a 12-month course with infliximab. Intriguingly, such conversion from seropositivity to seronegativity was not accompanied by simultaneous reduction of ASCA [19].

An experienced group of Investigators from Belgium have tested 164 patients with CD for anti-GP2 antibodies, using the commercially-available assay which was used in the present study [21]. Op De Beéck et al. reported a sensitivity of anti-GP2 antibodies in patients with $\mathrm{CD}$ of $21 \%$. However, it is not clear at what time points these serum samples were tested for autoantibody reactivity [21]. Also, the overall prevalence of $\mathrm{PAB}$ in the Belgian CD cohort was significantly lower than that of the present study (31\% vs. $44 \%$ ), and therefore a lower prevalence of anti-GP2 in the Belgian IBD population was not a surprising finding. The strikingly negative correlation between lower gastrointestinal tract localization of Crohn's disease and presence of anti-GP2 was a characteristic feature of both studies. Finally, Op De Beéck et al. have failed to associate anti-GP2 seropositivity with other clinical correlates, when we have found that the presence of these antibodies is more prevalent in patients who present with $\mathrm{CD}$ at a younger age, in addition to those with stricturing disease behaviour. Immediate comparisons of the statistical values amongst the two studies cannot be made, as the Belgian study has been published in the form of a short Letter to the Editor with limited access to the wealth of the statistical analyses' data [19]. Even if there was a consensus amongst the two studies, it would be very premature to comment on the clinical significance of anti-GP2 antibodies in IBD, as the clinical relevance of these antibodies cannot be assessed based on two studies. Care 
must be exercised also, when extrapolating conclusions regarding the effect of biological agents in the behaviour of anti-GP2 antibodies as the Belgian investigators did not find a profound effect of infliximab and adalimumab in patients followed up for 6-44 months [19,21].

Exchange of serum samples among researchers and large, multi-centre, prospective studies are needed to better delineate the diagnostic and clinical relevance of anti-GP2 pancreatic antibodies and their behaviour over the course of the disease in patients with inflammatory bowel diseases.

The development of a commercially-available ELISA based on recombinant human GP2 will allow for the accurate detection of GP2-specific pancreatic autoantibodies in routine laboratory practice and the initiation of longitudinal studies [18]. It would be of interest to know whether such studies will provide independent verification of the thesis supported by the present data that combined anti-GP2 and ASCA testing performs better than relying on tests limited to ASCA alone.

\section{Conclusions}

Anti-GP2, constituting novel CD specific autoantibodies, is positive in about $30 \%$ of patients with $C D$ and their detection may be of clinical significance. Anti-GP2 IgG and IgA, constituting novel CD specific autoantibodies, appear to be associated with distinct disease phenotypes identifying patients at a younger age, with ileocolonic location, and stricturing behaviour with perianal disease.

\section{Abbreviations \\ ASCA: Antibody to mannan of Saccharomyces cerevisiae; BD: Blood donor; CD: Crohn's disease; Cl: Confidence interval; CV: Coefficient of variation; ELISA: Enzyme-linked immunosorbent assay; FAS: Functional assay sensitivity; GPI: Glycosyl phosphoinositol; GP2: Zymogen granule membrane glycoprotein 2; IBD: Inflammatory bowel disease; IIF: Indirect immunofluorescence; LR: Likelihood ratio; M cell: Microfold or membranous cell; OD: Optical density; PAB: Pancreatic autoantibody; PP: Peyer's patches; rho: Spearman's rank coefficient of correlation; ROC: Receiver operating characteristics; RT: Room temperature; UC: Ulcerative colitis.}

\section{Competing interests}

Dirk Roggenbuck is a shareholder of GA Generic Assays GmbH and Medipan $\mathrm{GmbH}$. The remaining authors declare that they have no competing financial interests.

\section{Authors' contributions}

Study concept and design, analysis and interpretation of data, drafting of the manuscript: Dimitrios P. Bogdanos; Study concept and design, acquisition of data, analysis and interpretation of data, drafting of the manuscript: Dirk Roggenbuck; Subject recruitment, acquisition and analysis of data: Dirk Reinhold and Thomas Wex; Subject recruitment, acquisition and analysis of data: Polychronis Pavlidis; Subject recruitment, interpretation of data: Ulrike von Arnim, Peter Malfertheiner; Subject recruitment, interpretation of data and manuscript preparation: Alastair Forbes; Study concept and design, acquisition of data, analysis and interpretation of data, drafting of the manuscript: Karsten Conrad; Subject recruitment, interpretation of data and manuscript preparation: Martin W. Laass. All authors read and approved the final manuscript.
}

Authors' information

Alastair Forbes, Karsten Conrad and Martin W Laass shared last authorship.

\section{Acknowledgements}

DPB is supported by the Higher Education Funding Council of England (HEFCE); AF has obtained support from the Biomedical Research Centre hosted at UCL and UCLH by the UK NIHR. This work was supported by the Brandenburg Ministry of Economics and European Union grant 80130073.

\section{Author details}

${ }^{1}$ Division of Transplantation Immunology and Mucosal Biology, King's College London School of Medicine at King's College Hospital, Denmark Hill Campus, Bessemer Road, London SE5 9RJ, UK. ${ }^{2}$ GA Generic Assays GmbH, 15827 Dahlewitz, Berlin, L.-Erhard-Ring 3, Germany. ${ }^{3}$ Institute of Molecular and Clinical Immunology, Otto-von-Guericke University Magdeburg, 39120 Magdeburg, Leipziger Str. 44, Germany. ${ }^{4}$ Department of Gastroenterology, Hepatology and Infectious Diseases, Otto-von-Guericke University Magdeburg, 39120 Magdeburg, Leipziger Str. 44, Germany. ${ }^{5}$ Department of Gastroenterology and Clinical Nutrition, University College Hospital, London, UK. ${ }^{6}$ Institute of Immunology, Technical University Dresden, 01307 Dresden, Fetscherstraße 74, Germany. ${ }^{7}$ Children's Hospital, Technical University

Dresden, 01307 Dresden, Fetscherstraße 74, Germany.

Received: 1 February 2012 Accepted: 28 July 2012

Published: 6 August 2012

\section{References}

1. Walker DG, Williams HR, Kane SP, Mawdsley JE, Arnold J, McNeil I, Thomas HJ, Teare JP, Hart AL, Pitcher MC, Walters JR, Marshall SE, Orchard TR: Differences in inflammatory bowel disease phenotype between South Asians and Northern Europeans living in North West London, UK. Am J Gastroenterol 2011, 106:1281-1289.

2. Bogdanos DP, Rigopoulou El, Smyk DS, Roggenbuck D, Reinhold D, Forbes A, Laass MW, Conrad K: Diagnostic value, clinical utility and pathogenic significance of reactivity to the molecular targets of Crohn's disease specific-pancreatic autoantibodies. Autoimmun Rev 2011, 11:143-148.

3. Baumgart DC, Carding SR: Inflammatory bowel disease: cause and immunobiology. Lancet 2007, 369:1627-1640.

4. Logan I, Bowlus CL: The geoepidemiology of autoimmune intestinal diseases. Autoimmun Rev 2010, 9:A372-A378.

5. Wehkamp J, Koslowski M, Wang G, Stange EF: Barrier dysfunction due to distinct defensin deficiencies in small intestinal and colonic Crohn's disease. Mucosal Immunol 2008, S1:67-74.

6. Roggenbuck D, Hausdorf G, Martinez-Gamboa L, Reinhold D, Büttner T, Jungblut PR, Porstmann T, Laass MW, Henker J, Büning C, Feist E, Conrad K: Identification of GP2, the major zymogen granule membrane glycoprotein, as the autoantigen of pancreatic antibodies in Crohn's disease. Gut 2009, 58:1620-1628.

7. Seibold F, Weber $P$, Jenss $H$, Wiedmann $\mathrm{KH}$ : Antibodies to a trypsin sensitive pancreatic antigen in chronic inflammatory bowel disease: specific markers for a subgroup of patients with Crohn's disease. Gut 1991, 32:1192-1197.

8. Stöcker W, Otte M, Ulrich S, Normann D, Finkbeiner H, Stöcker K, Jantschek G, Scriba PC: Autoimmunity to pancreatic juice in Crohn's disease. Results of an autoantibody screening in patients with chronic inflammatory bowel disease. Scand J Gastroenterol Supp/ 1987, 139:41-52.

9. LeBel $D$, Beattie M: The major protein of pancreatic zymogen granule membranes (GP-2) is anchored via covalent bonds to phosphatidylinositol. Biochem Biophys Res Commun 1988, 154:818-823.

10. Rindler MJ, Hoops TC: The pancreatic membrane protein GP-2 localizes specifically to secretory granules and is shed into the pancreatic juice as a protein aggregate. Eur J Cell Biol 1990, 53:154-163.

11. Hase K, Kawano K, Nochi T, Pontes GS, Fukuda S, Ebisawa M, Kadokura K, Tobe T, Fujimura Y, Kawano S, Yabashi A, Waguri S, Nakato G, Kimura S, Murakami T, limura M, Hamura K, Fukuoka S, Lowe AW, Itoh K, Kiyono H, Ohno H: Uptake through glycoprotein 2 of $\mathrm{FimH}(+)$ bacteria by $\mathrm{M}$ cells initiates mucosal immune response. Nature 2009, 462:226-230.

12. Hölzl MA, Hofer J, Kovarik JJ, Roggenbuck D, Reinhold D, Goihl A, Gärtner M, Steinberger $P$, Zlabinger GJ: The zymogen granule protein 2 (GP2) binds to scavenger receptor expressed on endothelial cells I (SREC-I). Cell Immunol 2011, 267:88-93. 
13. Conrad K, Schmechta H, Klafki A, Lobeck G, Uhlig HH, Gerdi S, Henker J: Serological differentiation of inflammatory bowel diseases. Eur J Gastroenterol Hepatol 2002, 14:129-135.

14. Bossuyt $X$ : Serologic markers in inflammatory bowel disease. Clin Chem 2006, 52:171-181.

15. Lakatos PL, Papp M, Rieder F: Serologic antiglycan antibodies in inflammatory bowel disease. Am J Gastroenterol 2011, 106:406-412.

16. Ferrante $M$, Henckaerts $L$, Joossens $M$, Pierik M, Joossens $S$, Dotan $N$ Norman GL, Altstock RT, Van Steen K, Rutgeerts P, Van Assche G, Vermeire S: New serological markers in inflammatory bowel disease are associated with complicated disease behaviour. Gut 2007, 56:1394-1403.

17. Rieder F, Schleder S, Wolf A, Dirmeier A, Strauch U, Obermeier F, Lopez R, Spector L, Fire E, Yarden J, Rogler G, Dotan N, Klebl F: Serum anti-glycan antibodies predict complicated Crohn's disease behavior: a cohort study. Inflamm Bowel Dis 2010, 16:1367-1375.

18. Roggenbuck D, Reinhold D, Wex T, Goihl A, von Arnim U, Malfertheiner $P$, Büttner T, Porstmann T, Porstmann S, Liedvogel B, Bogdanos DP, Laass MW, Conrad K: Autoantibodies to GP2, the major zymogen granule membrane glycoprotein, are new markers in Crohn's disease. Clin Chim Acta 2011, 412:718-724.

19. Roggenbuck D, Reinhold D, Wex T, von Arnim U, Malfertheiner P, Sturm A, Werner L, Bogdanos DP, Laass MW, Conrad K: Authors' response: antibodies to GP2, the major zymogen granule membrane glycoprotein, are specific for Crohn's disease and may reflect treatment response. Gut 2012, 61:164-165.

20. Pavlidis P, Forbes A, Bogdanos DP: Antibodies to glycoprotein 2 (GP2) in patients with inflammatory bowel diseases from UK. Clin Chim Acta 2011, 412:1163-1164.

21. Op De Beéck K, Vermeire S, Rutgeerts P, Bossuyt X: Antibodies to GP2, the major zymogen granule membrane glycoprotein, in inflammatory bowel diseases. Gut 2012, 61:162-164.

22. Lakatos PL, Altorjay I, Szamosi T, Palatka K, Vitalis Z, Tumpek J, Sipka S, Udvardy M, Dinya T, Lakatos L, Kovacs A, Molnar T, Tulassay Z, Miheller P, Barta Z, Stocker W, Papp J, Veres G, Papp M: Pancreatic autoantibodies are associated with reactivity to microbial antibodies, penetrating disease behavior, perianal disease, and extraintestinal manifestations, but not with NOD2/CARD15 or TLR4 genotype in a Hungarian IBD cohort. Inflamm Bowel Dis 2009, 15:365-374.

23. Seibold F, Mörk H, Tanza S, Müller A, Holzhüter C, Weber P, Scheurlen M: Pancreatic autoantibodies in Crohn's disease: a family study. Gut 1997, 40:481-484.

24. Silverberg MS, Satsangi J, Ahmad T, Arnott ID, Bernstein CN, Brant SR, Caprilli R, Colombel JF, Gasche C, Geboes K, Jewell DP, Karban A, Loftus EV Jr, Peña AS, Riddell RH, Sachar DB, Schreiber S, Steinhart AH, Targan SR, Vermeire S, Warren BF: Toward an integrated clinical, molecular and serological classification of inflammatory bowel disease: report of a Working Party of the 2005 Montreal World Congress of Gastroenterology. Can J Gastroenterol 2005, 19(Suppl A):5-36.

25. IBD Working Group of the European Society for Paediatric Gastroenterology, Hepatology and Nutrition: Inflammatory bowel disease in children and adolescents: recommendations for diagnosis-the Porto criteria. J Pediatr Gastroenterol Nutr 2005, 41:1-7.

26. Stange EF, Travis SP, Vermeire S, Beglinger C, Kupcinkas L, Geboes K, Barakauskiene A, Villanacci V, Von Herbay A, Warren BF, Gasche C, Tilg H, Schreiber SW, Schölmerich J, Reinisch W: European evidence based consensus on the diagnosis and management of Crohn's disease: definitions and diagnosis. Gut 2006, 55(Suppl 1):i1-i15.

27. Wong SM, Lowe AW: Sequence of the CDNA encoding human GP-2, the major membrane protein in the secretory granule of the exocrine pancreas. Gene 1996, 171:311-312.

28. Zöphel K, Wunderlich G, Kotzerke J, von Landenberg P, Roggenbuck D: M22 based (manual) ELISA for TSH-receptor antibody (TRAb) measurement is more sensitive than 2nd generation TRAb assays. Clin Chim Acta 2009, 403:266.

29. Egerer K, Roggenbuck D, Hiemann R, Weyer MG, Büttner T, Radau B, Krause $R$, Lehmann B, Feist E, Burmester GR: Automated evaluation of autoantibodies on human epithelial-2 cells as an approach to standardize cell-based immunofluorescence tests. Arthritis Res Ther 2010, 12:R40.
doi:10.1186/1471-230X-12-102

Cite this article as: Bogdanos et al:: Pancreatic-specific autoantibodies to glycoprotein 2 mirror disease location and behaviour in younger patients with Crohn's disease. BMC Gastroenterology 2012 12:102.

\section{Submit your next manuscript to BioMed Central and take full advantage of:}

- Convenient online submission

- Thorough peer review

- No space constraints or color figure charges

- Immediate publication on acceptance

- Inclusion in PubMed, CAS, Scopus and Google Scholar

- Research which is freely available for redistribution

Submit your manuscript at www.biomedcentral.com/submit
C) BioMed Central 